\title{
As Configurações Subjetivas do Câncer: um Estudo de Casos em uma Perspectiva Construtivo-Interpretativa
}

Cancer Subjective Configurations : A Case Study in a Constructive-Interpretative Approach

Las Configuraciones Subjetivas del Cáncer: Un Estudio de Casos en Una Perspectiva ConstructivoInterpretativa

Fernando Luis González Rey

Centro

Universitário de Brasília
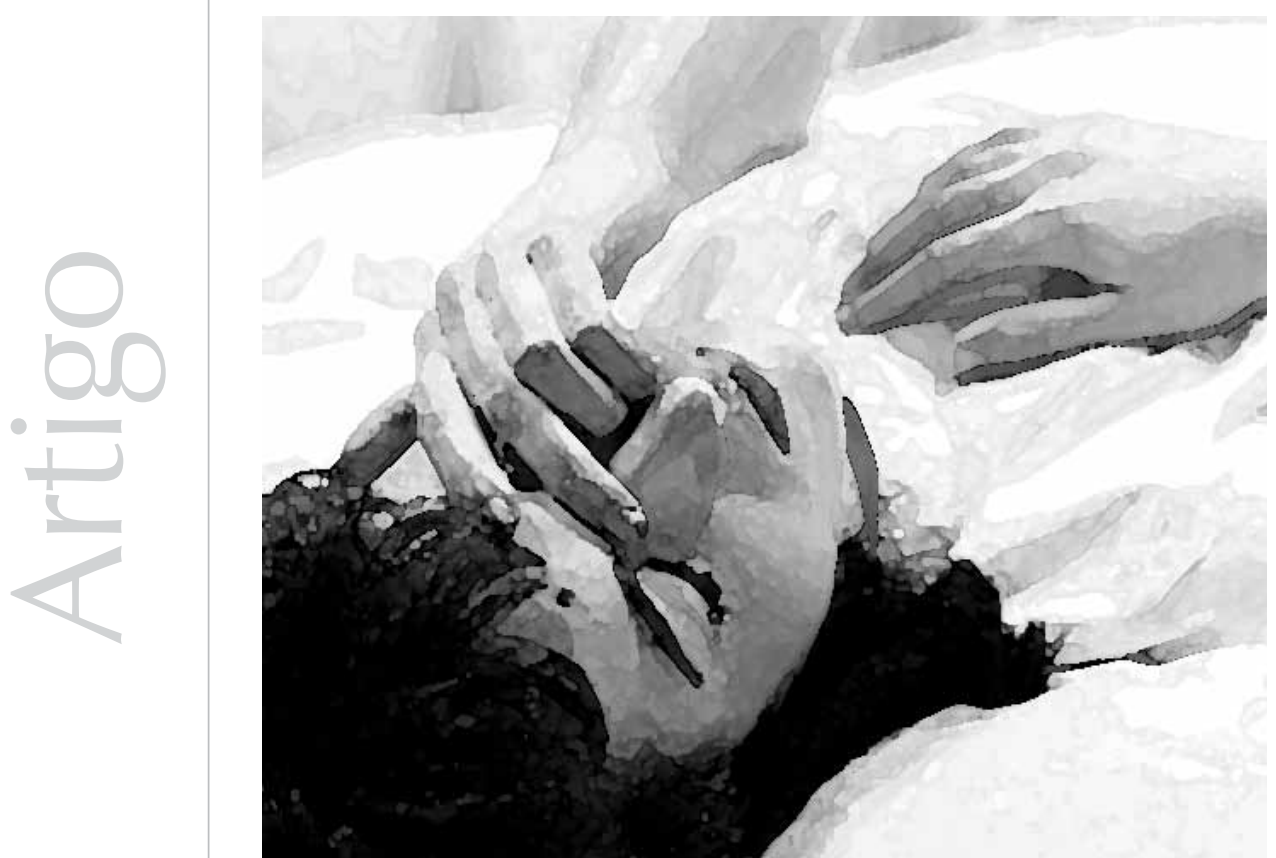
Resumo: O presente artigo aborda o estudo das configurações subjetivas do câncer a partir de uma visão da subjetividade em uma perspectiva histórico-cultural. A pesquisa foi realizada através do estudo de casos em mulheres com diferentes tipos de câncer. A aproximação metodológica se apoiou na epistemologia qualitativa, enfatizando o caráter construtivo-interpretativo e dialógico da pesquisa. No artigo, são discutidos dois casos, através dos quais se tenta demonstrar o processo de construção da informação nesse tipo de pesquisa. O processo de construção da informação se apoia em hipóteses levantadas pelo pesquisador no curso da pesquisa, que se apoiam, por sua vez, em indicadores construídos pelo próprio pesquisador no processo de construção da informação. A convergência de diferentes indicadores em relação a uma hipótese a transforma em uma construção teórica sobre a questão estudada, trazendo inteligibilidade sobre os possíveis sentidos subjetivos relacionados com as experiências de se viver com câncer.

Palavras-chave: Configuração subjetiva. Câncer. Sentido subjetivo. Subjetividade.

\begin{abstract}
This paper is oriented to the study of cancer subjective configurations based on the understanding of subjectivity from a historical-cultural standpoint. The research was carried out through the case study of women who had different types of cancer. It was used a constructive-interpretative methodological approach based on the qualitative epistemology. Two cases by which the author attempts to demonstrate how the construction of information is done under this qualitative research orientation are discussed in the paper. The construction of information is oriented by the hypotheses the researcher arose based on the indicators of the research process. When different indicators converge in regard to one hypothesis, it becomes a theoretical construction concerning the studied topic. This theoretical construction brings into light possible subjective senses and configurations related to the experience of living with cancer.
\end{abstract}

Keywords: Subjective configuration. Cancer. Subjective sense. Subjectivity.

Resumen: El presente artículo aborda el estudio de las configuraciones subjetivas del cáncer a partir de una visión de la subjetividad en una perspectiva histórico-cultural. La pesquisa fue realizada a través del estudio de casos en mujeres con diferentes tipos de cáncer. La aproximación metodológica se apoyó en la epistemología cualitativa, enfatizando el carácter constructivo-interpretativo y dialógico de la pesquisa. En el artículo, son discutidos dos casos, a través de los cuales se intenta demostrar el proceso de construcción de la información en ese tipo de pesquisa. El proceso de construcción de la información se apoya en hipótesis recogidas por el investigador en el curso de la pesquisa, que se apoyan, por su vez, en indicadores construidos por el propio investigador en el proceso de construcción de la información. La convergencia de diferentes indicadores en relación a una hipótesis la transforma en una construcción teórica sobre la cuestión estudiada, trayendo inteligibilidad sobre los posibles sentidos subjetivos relacionados con las experiencias de vivir con cáncer.

Palabras clave: Configuración subjetiva. Cáncer. Sentido subjetivo. Subjetividad.

As doenças crônicas representam um importante campo de estudo para a Psicologia, considerando o impacto que têm na subjetividade dos pacientes bem como a importância do envolvimento dos mesmos nas mudanças de seu modo de vida, as quais são essenciais tanto para o tratamento das doenças como para assegurar a sua qualidade de vida.

Até hoje, as ciências da saúde, profundamente apoiadas no modelo biomédico tradicional, não consideram no devido lugar a importância dos aspectos subjetivos sociais e culturais nos processos de saúde-doença, apesar das grandes mudanças ocorridas em determinados setores das ciências da saúde em relação a esses elementos nos últimos 20 anos.

No presente artigo, iremos apresentar, a partir da perspectiva histórico-cultural sobre a subjetividade, um estudo qualitativo com o objetivo de produzir certa inteligibilidade sobre as diferentes configurações subjetivas do câncer em pessoas. A partir de nosso referencial, temos como perspectiva transpor o nível puramente descritivo das falas dos sujeitos estudados, para identificar os sentidos subjetivos que configuram a experiência do adoecer nesses pacientes.

A questão da subjetividade, que tem sido desenvolvida em diferentes campos teóricos 
na Psicologia, é apresentada neste trabalho a partir da perspectiva histórico-cultural, na qual o fenômeno subjetivo é considerado não apenas em seu aspecto individual mas também constituinte dos diferentes espaços sociais da atividade humana (Castoriadis, 1982; González Rey, 2002).

A partir do posicionamento teórico que serviu de base à pesquisa que fundamenta este artigo, tento apresentar o valor heurístico da teoria histórico-cultural para o campo da saúde, uma vez que essa teoria, tradicionalmente, tem sido mais associada às áreas da Psicologia da educação e, mais recentemente, à Psicologia social.

Embora tenha se desenvolvido no Brasil um importante campo de pesquisa sobre os aspectos psicológicos do câncer, como é o caso da psico-oncologia (conforme Ribeiro, 1994; Gimenes, 1997, entre outros), o qual tem constituído um espaço particular de pesquisa que integra trabalhos apoiados em diferentes perspectivas teóricas, o presente estudo não se apoia nos pressupostos desenvolvidos por essa interface disciplinar. Tendo em vista que nosso interesse é estudar a dimensão subjetiva dessa doença, buscamos nossa fundamentação teórica na perspectiva histórico-cultural, que nos aponta a relevância da questão da subjetividade na constituição do ser humano.

\section{A noção de subjetividade: sua especificidade em uma perspectiva histórico-cultural}

\footnotetext{
A Psicologia vai aparecer e se estabelecer como campo científico no contexto da modernidade pautando-se em princípios teóricos e epistemológicos de outros saberes mais desenvolvidos na época: a Medicina, o saber jurídico e as ciências naturais, principalmente a Física clássica. No início
}

do século XX, ela se divide em um conjunto de tendências, umas dominantes na esfera acadêmica, e outras que caracterizam sua prática clínica.

A área acadêmica é dominada, em particular nos Estados Unidos, por um empirismo crescente que também teve forte expressão, mesmo que não tão homogênea, na Europa. Nesse período, entre final do século XIX e primeira metade do $X X$, a pesquisa em Psicologia se identificou rigidamente com a experimentação, e sua orientação prática esteve dominada pela psicometria, apoiada nos mesmos princípios epistemológicos positivistas que dominaram a pesquisa. Foi esse o período que K. Danziger (1990) definiu como metodolatria da Psicologia e que S. Koch (1992), outro grande historiador da Psicologia, definiu como fetichismo metodológico.

Nesse período, temos também o desenvolvimento da psicanálise, que, tendo suas bases no campo da Medicina, apareceu como teoria associada à prática clínica e orientada para o estudo do inconsciente em uma perspectiva dinâmica. Com a psicanálise, o tema da subjetividade, mesmo que não definida de forma explícita por Freud, aparece associado à estrutura psíquica da pessoa, na qual o inconsciente representa o núcleo dinâmico essencial.

A psicanálise, como qualquer outra teoria que se institucionalizou e se perpetuou na história da Psicologia, não representou uma teoria monolítica, mas caracterizou-se como a evolução de uma complexa família de teorias que, organizadas ao redor de alguns núcleos teóricos compartilhados, tem se desenvolvido de forma permanente. Uma das características mais marcantes dessa evolução tem sido o reconhecimento crescente do aspecto social e da cultura na formação da subjetividade (Castoriadis, 1982; Guattari, 1992; Elliott, 
1992). De certa forma, o conceito de complexo em Jung vai também nessa direção.

Também no início do século $X X$ vai se desenvolver a psicologia soviética, que, dentro de sua pluralidade, se preocupa com o caráter sistêmico e complexo da psique humana. Vigotski (1987) e Rubinstein (1967), dois autores clássicos dessa psicologia, tomam os temas da personalidade e da motivação como centrais em suas obras.

O tema da subjetividade não aparece de forma explícita no campo da psicologia soviética em razão do caráter materialista mecanicista que dominava a interpretação do marxismo, interpretação essa realizada pelo grupo que estava no poder político e que terminou se tornando parte do imaginário da própria sociedade soviética. Os teóricos soviéticos se aproximam desse tema de forma implícita, ao buscarem os sistemas dinâmicos do funcionamento da psique através da unidade do cognitivo e do afetivo. Tanto Vigotski quanto Rubinstein consideravam esses sistemas processos desenvolvidos dentro da cultura. A relevância da categoria de reflexo para essa psicologia, porém, que ganhou peso político a partir de sua definição por Lênin, limitou a compreensão do caráter gerador da psique, reduzindo-o à noção de reflexo.

O conceito de subjetividade que trabalharei neste artigo parte de um dos últimos conceitos desenvolvidos por Vigotski, o conceito de sentido, que, na obra desse autor, nos aproxima de uma compreensão da unidade do afetivo e cognitivo, o que não é equivalente à soma de ambos os processos tomados em separado, mas a uma relação dialética entre esses elementos. É na relação que Vigotski estabelece entre o sentido e a personalidade que se abre uma importante perspectiva para nova definição de subjetividade. Sobre essa relação, que ele apenas apresenta, mas não desenvolve no curso de sua obra, escreve: "A palavra é uma fonte infinita de novos problemas. Seu sentido nunca é completo. Finalmente, o sentido da palavra depende da compreensão da palavra como todo e da estrutura interna da personalidade" (Vigotski, 1987, p. 276).

Pelo caráter incompleto e contraditório do termo sentido encontrado nas formulações de Vigotski, assim como pelas inúmeras definições de sentido existentes na literatura (Schpet, 1996; Bakhtin, 1997; Merleau-Ponty, 1991, entre outros), considerei importante introduzir o conceito de sentido subjetivo como a unidade teórica para o estudo da subjetividade. Quero me referir ao termo sentido subjetivo como unidade psicológica que expressa o caráter subjetivo dos processos psíquicos humanos nas condições da cultura (González Rey, 2002, 2005, 2007). Assim, o sentido subjetivo se caracteriza por:

1 - Estar sempre envolvido na subjetividade como sistema. O sentido subjetivo representa um momento de unidade e de confrontação entre a subjetividade social e individual, e aparece na ação do sujeito estreitamente associado à organização atual de sua subjetividade individual assim como aos processos da subjetividade social, dentro dos diferentes espaços e contextos em que a pessoa atua. O sentido subjetivo não é um reflexo, é uma produção subjetiva que se organiza em configurações subjetivas que representam verdadeiros sistemas em desenvolvimento;

2 - Expressar a unidade inseparável do simbólico com o emocional, unidade onde cada um desses aspectos evoca o outro, sem se converter em sua causa. O emocional e o simbólico se expressam em uma relação recursiva nos sentidos subjetivos, como processos sempre em desenvolvimento; 
3 - Estarem sempre relacionados à definição de espaços simbólicos produzidos pela cultura, como gênero, moralidade, religião, parentesco, sexualidade, etc., mas alimentarem-se de emoções singulares configuradas na história de cada sujeito.

Nesse caso, em relação ao campo da saúde, as representações das doenças se convertem em uma produção social de caráter simbólico, em relação ao qual é construída uma multiplicidade de sentidos subjetivos em decorrência dos discursos e das representações sociais em que se define a construção social da doença e das configurações subjetivas dos sujeitos que se relacionam nesses espaços sociais.

O conceito de sentido subjetivo tem as seguintes características para que se possa entender a dimensão psíquica das doenças:

1 - Nenhuma doença em si é portadora de um sentido subjetivo. Os sentidos subjetivos se produzem como resultado da articulação dialética entre as emoções e os processos simbólicos, que aparecem como o resultado dos modos como cada sujeito vive sua doença. Viver a doença não é apenas uma expressão da relação direta do sujeito com as suas consequências, mas das produções do sujeito sobre ela a partir de seus recursos psicológicos atuais;

2 - Não existem elementos universais a partir dos quais se possa predizer as possibilidades de uma doença, tendo em vista o tipo de organização psicológica da pessoa. A doença é uma complexa organização de fatores diferentes que, em sua integração e diante de determinadas condições, produzem uma mudança qualitativa no funcionamento do organismo. Os sentidos subjetivos são apenas um dos elementos que participam desse complexo processo;
3 - Os sentidos subjetivos têm caráter patogênico não pelo seu conteúdo, mas pelo tipo de emoções neles envolvidas. Esse é um processo que não é regulado racionalmente pelo sujeito, embora o seu posicionamento racional seja parte do processo de produção dos sentidos subjetivos.

Partindo do que foi colocado, reconhecemos que os sentidos subjetivos estão em permanente processo, como momentos de subjetivação da ação do sujeito em seus diferentes contextos. Atribuímos a eles também uma forma de organização em que a história do sujeito está presente como organização subjetiva do vivido. Essas formas de organização da subjetividade individual constituem as configurações subjetivas, que não são causas da ação do sujeito, mas que representam apenas mais uma fonte de produção de sentido subjetivo dentro da ação.

Os sentidos subjetivos não aparecem explícitos de forma direta, na expressão intencional do sujeito, não estão dados no que o sujeito fala. Eles aparecem de forma indireta, por expressões muito diversas e não associadas de forma imediata entre si. Os sentidos subjetivos têm que ser definidos em um processo construtivo-interpretativo por parte do pesquisador. Esse fato implicou um questionamento epistemológico que levou à definição da epistemologia qualitativa (González Rey, 1997) como fundamento de uma nova proposta de pesquisa capaz de responder aos desafios do estudo da subjetividade.

A subjetividade assim representada, através dos sentidos subjetivos e das configurações subjetivas que se desenvolvem na ação do sujeito, é inseparável da rede simbólicosubjetiva que configura cada ação humana. Nessa rede, emoções e processos simbólicos atuais são inseparáveis de outros sentidos 
subjetivos que resultaram dos efeitos colaterais de experiências já vividas, e que hoje representam a configuração subjetiva da pessoa em que se expressaram as experiências anteriores. Nessa forma de compreender a subjetividade, é rompida definitivamente a tendência de compreendêla a priori, através de categorias universais.

\section{Metodologia}

O presente trabalho parte de uma metodologia qualitativa de caráter construtivo-interpretativo que se apoia nos princípios da epistemologia qualitativa (González Rey, 1997, 1999, 2005): o caráter construtivo-interpretativo do processo de produção do conhecimento, a comunicação como espaço de produção da informação e o reconhecimento do singular como instância de produção de conhecimento científico. Nessa perspectiva, o nosso posicionamento metodológico se apresenta como um processo dialógico orientado ao envolvimento ativo dos participantes da pesquisa, condição essencial para que os sentidos subjetivos possam emergir no processo. Defendemos uma perspectiva metodológica que parte de uma epistemologia da construção, e não da resposta.

Assim, o sujeito participante da pesquisa é compreendido a partir de sua expressão aberta, autêntica, capaz de expressar seus desejos, necessidades e contradições, processos esses que não aparecem de forma direta na palavra, mas através de elementos indiretos que recebem significado pela interpretação do pesquisador. A pesquisa se baseia em uma relação dialógica orientada para a abertura de novos espaços de troca e reflexão que, pela sua autenticidade, vão envolver as emoções do sujeito, condição essencial para a emergência dos sentidos subjetivos. O pesquisador aparece envolvido em uma troca permanente de ideias com as pessoas que participam do projeto, convertendo o espaço da pesquisa em novo espaço social para os participantes.

Nessa perspectiva, os instrumentos se tornam simples indutores de informação, recursos para conseguir a expressão comprometida das pessoas que se expressam através deles. Os instrumentos são usados dentro de uma perspectiva que vai além do instrumentalismo, tão dominante na Psicologia. Não são os critérios de sua construção que definem o valor dos instrumentos, mas é a qualidade da informação que eles propiciam que deve ser construída e interpretada pelo pesquisador. Nesse sentido, supera-se algo muito bem colocado por Adorno ao expressar: "Em geral, a objetividade da pesquisa empírica é uma objetividade dos métodos, não do pesquisado" (Adorno, 2001, p. 22).

Os instrumentos usados na pesquisa foram o complemento de frases e de várias sessões de conversações individuais com cada participante. O complemento de frases não foi trabalhado como prova projetiva, como tem sido usado na Psicologia, mas como instrumento aberto para o estudo da subjetividade, segundo a definição de instrumento assumida neste trabalho (González Rey \& Mitjáns Martinez, 1989; González Rey, 1999, 2005) O complemento de frases se organiza em torno de um número variável de frases que a pessoa estudada deve completar, e que sempre tomam formas singulares a partir do que é relevante para quem as responde.

O complemento de frases é sempre apresentado aos participantes da pesquisa depois que o clima dialógico foi constituído dentro do grupo pesquisado. Cada instrumento usado na pesquisa é um momento de um processo dialógico, que se caracteriza por uma 
sequência de conversas com os participantes da pesquisa. Qualquer instrumento de expressão escrita como o que foi referido antes pode desdobrar-se em um instrumento dialógico em si quando, logo após a análise do pesquisador, é devolvido aos sujeitos com o objetivo de estabelecer uma conversa sobre o que a pessoa pensa, tendo em vista aquilo que escreveu. Esses desdobramentos nos permitem, com frequência, a obtenção de uma informação muito rica sobre o sujeito estudado.

Os casos apresentados neste artigo foram extraídos da pesquisa em andamento Identidade e representação subjetiva da doença: seu significado para repensar a prevenção de saúde no câncer e no enfarto do miocárdio. Atualmente, somos um total de 35 pessoas, que trabalham, usando dinâmicas grupais e conversas individuais, com grupos focais de até 10 participantes sobre temas que, em geral, são decididos pelos próprios participantes. O grupo sempre começa depois de uma sequência de conversas individuais.

Nos casos que apresentamos a seguir, foram realizadas varias sessões de conversa de até uma hora e meia cada uma (as conversas não são reguladas por um tempo padronizado, mas sua duração depende da riqueza, do envolvimento e da necessidade vivenciada pelas pessoas envolvidas) e, complementarmente, foi usado o instrumento complemento de frases, que foi apresentado quando o vínculo já havia sido estabelecido em conversas individualizadas (Bayer, 2004; Silva, 2005).

Os casos foram trabalhados como estudo de casos, sem nenhum tipo de padronização dos instrumentos ou dos procedimentos seguidos. A relevância do estudo de caso nesse tipo de pesquisa se caracteriza pelos elementos que esses casos aportam a um modelo teórico em desenvolvimento, capaz de gerar inteligibilidade sobre os sentidos e as configurações subjetivas associadas ao câncer. Não se pretende chegar à configuração subjetiva do câncer, pois não existe somente uma, mas muitas e diversas, dependendo dos recursos subjetivos da pessoa e de seus contextos de vida social.

A generalização, nesse tipo de pesquisa, está muito mais associada à qualidade do modelo teórico em andamento, formado pelas hipóteses que vão se legitimando no curso da pesquisa, pelos sistemas de informação que ganham visibilidade nas construções teóricas. Os modelos teóricos aparecem como resultado da construção teórica sobre um sistema de informação empírica, que se legitima pela sua capacidade de gerar inteligibilidade sobre aspectos dessa informação que, fora dessas representações, não teriam significado para o problema em estudo. Como expressa Mitchell (1983), “... o problema pode ser tratado em termos de generalidade, mais em relação a proposições teóricas que a população ou universos" (Mitchell como citado por Bryman \& Burguess, 1994, p.160).

Os modelos teóricos representam uma construção que permite dar visibilidade a aspectos e formas de organização do problema estudado, os quais não são acessíveis de forma direta pela observação, mas que ganham visibilidade para o pesquisador em suas múltiplas e recursivas inter-relações, por meio do modelo produzido. Um instrumento muito importante na organização do modelo teórico que acompanha a construção do conhecimento sobre o problema da pesquisa é a definição de indicadores no curso do processo de análise da informação empírica. Os indicadores são significados hipotéticos que se definem a partir de elementos ou conjuntos de elementos da informação analisada (González Rey, 1999, p. 112). 
Os indicadores são significados que o pesquisador vai gerando perante certos trechos de informação. A concorrência de indicadores diferentes em relação a um mesmo significado permite a definição de hipóteses que, na sua inter-relação, definem o modelo teórico.

Finalmente, em relação a nossa aproximação metodológica, é importante destacar o lugar que atribuímos às hipóteses dentro desse processo construtivo-interpretativo. As hipóteses representam construções em andamento, que não têm como objetivo a verificação empírica, mas que representam o fio teórico condutor usado pelo pesquisador para integrar o complexo sistema de informações, ideias e reflexões que, no curso da pesquisa, vão conduzindo as construções que definiram o modelo teórico em uma pesquisa concreta.

Como destacam Bourdieu, Chamboredon e Passeron (1975),

um sistema de hipóteses contém seu valor epistemológico na coerência que constitui sua plena vulnerabilidade; por um lado, um só fato pode questioná-lo integralmente, e, por outro, construído sob as aparências fenomenais, não pode receber a confirmação imediata e fácil que os fatos, tomados em seu valor superficial, ou os documentos, em forma literal, proporcionariam. Em efeito, ao preferir expor-se a perder tudo a fim de ganhar tudo, o cientista confrontase a todo o momento com os fatos que interroga, aquilo que o respalda em seu questionamento dos fatos. (p. 92)

O modelo teórico é uma construção que não pretende aplicar conceitos de uma teoria assumida a priori, mas avançar no tecido de informações empíricas a partir de hipóteses que vão sendo geradas nesse processo com base nos indicadores levantados e que permitem dar significado, no caso concreto em estudo, a categorias do referente teórico assumido. Esse posicionamento está orientado para superar a forma direta e linear que, com frequência, é usada nas pesquisas psicológicas, categorias mais gerais associadas a um referente teórico para se referir a processos e eventos do nível empírico. Com isso, as categorias terminam se impondo como significados a priori, que não são construídos desde a especificidade da informação empírica que se analisa.

Antes de começar a pesquisa, foi feita uma reunião com os possíveis participantes, o que constituiu o cenário social de pesquisa (cf. González Rey, 2005), compreendido como o primeiro momento no qual o tema é apresentado de forma amena e instigante, que facilite o estabelecimento da comunicação entre o pesquisador e os participantes assim como o interesse dos participantes.

No presente artigo, serão apresentados dois estudos de caso com as seguintes características gerais :

- MG, mulher, 30 anos, mãe de dois filhos, um menino e uma menina, divorciada. Apresenta câncer na cabeça há, aproximadamente, cinco anos.

- MT, mulher, 50 anos, mãe de dois filhos, um menino e uma menina, casada, que fez mastectomia radical no ano 2000.

Ambas se ofereceram como voluntárias logo depois que a pesquisa e suas questões norteadoras foram apresentadas ante um grupo de mulheres submetidas ao tratamento do câncer. O fato de ambas terem recebido o diagnóstico de câncer no período de gravidez só foi conhecido logo depois de ter sido iniciado o processo de pesquisa. 


\section{Análise e construção da informação}

Tanto MG quanto MT tiveram o diagnóstico de câncer durante o período da gravidez de um dos filhos, o que confere as suas experiências um caráter muito particular no estudo das configurações subjetivas do câncer. Para ambas, a gravidez e os filhos constituem fontes de sentidos que marcaram a organização de suas configurações subjetivas em relação à doença.

MG expressa, durante a conversa: “(...) acho que se eu não estivesse grávida, de repente eu não teria encarado como eu encarei"; um pouco mais à frente, nesse mesmo encontro, ela afirma:

"(...) eu pensei: meu Deus, eu vou morrer! Só que, ao mesmo tempo, eu falei: 'não, eu não posso morrer. Eu acabei de ter um bebê, isso não é justo, minha filha esta aí'. Então era aquela coisa de ficar acordada de manhã e falar assim: 'eu vou morrer, mas eu vou viver mesmo até o último dia de minha vida, acreditando que eu vou viver'. Então, eu tô viva até hoje, e eu sei que vou ficar até mais um bom tempo".

Essas expressões representam um indicador da relevância da filha em uma produção simbólico-emocional associada à doença, mas que parece atuar como uma filosofia da vida que irá marcar não só o vínculo com a filha mas também a sua própria posição ante a vida. Essas reflexões, sem dúvida, estão carregadas de emoções que lhe permitem posicionar-se, centrar-se em um foco e desconhecer outros. A delimitação clara dos sentidos subjetivos (González Rey, 2002) envolvidos nessa forma de encarar a doença precisa de maiores informações. Observa-se como o posicionamento frente à doença decorre de uma avaliação do vínculo com a filha, e como a morte, decorrente da representação social do câncer, está presente, não em um sentido de desmobilização, mas como base motivacional de uma elaboração sobre o viver que, mais do que uma reflexão intelectual isolada, representa uma produção de sentido subjetivo, o que se evidencia na elaboração carregada de emoção que expressa quando afirma "eu vou viver mesmo até o último dia de minha vida", o que representa uma forma de se posicionar ante sua situação atual. É precisamente essa teia de processos simbólicos e emocionais em que, de forma simultânea, coexistem aspectos conscientes, intencionais e inconscientes, que definem uma configuração subjetiva, que representa um novo sistema em relação àqueles sentidos subjetivos que a ela dão origem.

Segundo a posição teórica sobre subjetividade assumida neste trabalho (González Rey, 2002, 2004, 2005), a subjetividade como sistema de configurações subjetivas é inconsciente, sendo a consciência o resultado das representações contidas na linguagem da pessoa. Os processos simbólico-emocionais em que aparece organizada na psique a experiência vivida não têm nenhuma relação imediata e direta com a consciência.

Os sentidos subjetivos não podem se substancializar, eles não são identificáveis pelo seu conteúdo, mas representam um sistema em que coexistem fenômenos diferentes, de diversas ordens e até contraditórios, que tomam uma expressão simbólico-emocional dominante sempre dentro de um contexto; de modo diferente das configurações subjetivas, os sentidos subjetivos expressam uma elevada variabilidade. A estabilidade de certa produção de sentidos subjetivos é dada pela organização de uma configuração subjetiva. Unida à trama subjetiva explicada antes, cabe destacar a capacidade do sujeito para se posicionar ativamente, a sua capacidade de decisão em relação à definição de um caminho 
vital frente à doença. Nessa capacidade de decisão, emerge, em todas as suas nuances, a pessoa como sujeito da doença, sujeito capaz de tomar posições, de elaborar seus medos e dores e de se posicionar de frente aos desafios subjetivamente produzidos (Touraine, 2004, 2006; González Rey, 2002).

A relevância dos filhos para sua produção subjetiva evidencia-se não apenas em múltiplos trechos da conversa mas também no complemento de frases, no que ela expressa :

- Meu maior medo: deixar meus filhos desamparados

- Minha preocupação principal: criar meus filhos

- Sempre que posso: brinco com meus filhos

- Amo: meus filhos

- Farei o possível para: conseguir criar meus filhos.

Essas frases, junto aos trechos apresentados da conversa, constituem um indicador do lugar dos filhos no desenvolvimento dos sentidos subjetivos associados à doença. Nas frases exemplificadas acima, o significado subjetivo dos filhos aparece não apenas frente a indutores diretos em frases em que, de forma direta, os filhos são mencionados, mas também frente a indutores indiretos; uma frase de particular relevância para avaliar o valor dos filhos na sua produção de sentidos subjetivos frente à doença é aquela em que afirma: "sempre que posso, brinco com seus filhos". Aqui se evidencia que eles não representam apenas uma preocupação, mas um interesse, uma fonte de prazer a que dedica seu tempo livre. Essa frase é também um indicador de que ela mantém sua alegria, sua disposição vital. A informação portadora de sentido subjetivo não é aquela enfatizada no plano intencional, mas a que expressa um estado emocional produzido na ação, além de qualquer juízo valorativo.
É precisamente a pluralidade de aspectos considerados que mostram como informações diversas convergem em seu valor simbólicoemocional, o que permite falar de sentidos; o sentido subjetivo sempre aparece no curso de uma construção, não pela mera descrição de quem fala.

O marco teórico assumido (González Rey, 2002, 2004, 2005) permite, a partir das categorias de sentido subjetivo e da configuração subjetiva, construir a diversidade de sentidos subjetivos associados à forma de viver a doença. Não é o câncer em si, mas suas configurações subjetivas que estão na base das expressões psicológicas da pessoa que adoece.

Em outro fragmento, MG expressa :

Tem determinado tempo que eu tô bem, que eu olho para mim, às vezes até esqueço, só lembro na sexta feira (o dia que vai à quimioterapia)... mas às vezes eu passo tão bem durante a semana que eu chego a esquecer. E já tem uma fase que eu já estou mais assim, eu não sei o que acontece que eu estou carente, sabe de, poxa, por que eu tenho isso?... Aí eu olho para meus filhos, aí vem: será que eu vou conseguir criar, será que eu vou conseguir ver a Maria na formatura, fazer a festinha de quinze anos dela?

Nesse trecho, vemos como sentidos subjetivos diferentes se entrelaçam, entram em tensão, alimentam-se de desdobramentos emocionais e simbólicos que vão em direções opostas. Nesse momento, observa-se como o estado emocional dominante que se apropria dela se desdobra em processos simbólicos, imagens, representações e reflexões que, por sua vez, são fontes de novas emoções, que se mantêm em desenvolvimento dentro de um processo de sentido subjetivo diferente daquele que aparece nos momentos de otimismo, de vontade de luta e de definição de projetos, que marcam a maior parte da sua vida. 
Novamente diante de situações como a descrita no último trecho citado de MG, ela volta a aparecer como sujeito que se posiciona frente a seus estados emocionais, o que a ajuda a reverter esse estado afetivo dominante e se converte em um elemento essencial na emergência dos sentidos subjetivos hegemônicos na configuração subjetiva da doença. Ela diz: "E... aí nessas horas eu dou uma parada, entro em contato com alguém que seja de confiança, ou da família e peço: 'oh! estou desse jeito, me ajuda!'”

Os sentidos subjetivos sofrem metamorfoses, são susceptíveis de desdobramentos, nos quais o que parecia se acompanhar de um tipo de emoção de repente se transforma em outras emoções. Nesse processo, coexistem momentos dominantes diferentes associados a sentidos subjetivos semelhantes que, em suas inter-relações com outros aspectos da vida psíquica frente a contextos diferentes, levam a novas emoções e processos simbólicos, como foi dito no trecho anterior. A subjetividade não é estática nem ocorre a priori em relação à trama vivida; ela é parte dessa trama, antecipando-se, mas também mudando no curso da vida desse sujeito.

A conversa, o contato com os outros representou, naquele momento de baixa relatado por ela, uma fonte de novas produções psicológicas, facilitadoras da emergência de novos sentidos subjetivos. Esses sentidos subjetivos que se tornaram dominantes podem ser subordinados em determinados momentos frente a outros. É importante destacar a relevância da decisão da pessoa na procura de atividades e relações capazes de produzir novos estados psíquicos.

MG mantém o seu interesse pela vida, pelos estudos, pelos seus projetos de vida.
Neste momento, namora D., e tem planos de casar-se logo. Seu posicionamento forte e aberto, expressão do sentido subjetivo hoje dominante na sua configuração da doença, se expressa na sua capacidade de luta, otimismo, vínculo com os filhos, interesses, amor pelos outros e triunfo frente à doença, o que aparece com clareza em sua reação frente ao ex-marido e em seu posicionamento atual em relação a ele. Sobre esse aspecto, ela disse:

Quando foi diagnosticado o tumor, o meu ex-marido passou a ser outra pessoa, ficou muito atencioso, muito ali colado, cuidando de mim, e isso se desgastou. Com o tempo, isso também foi se desgastando a ponto dele continuar vivendo a vida dele e dizer: 'olha, eu não tenho mais...' Eu não lembro qual o termo que ele utilizou, mas foi como se fosse assim: 'eu não tenho mais forças para continuar'. (...) E eu disse: 'eu não quero te obrigar a fazer nada, essa cruz é minha, e você não tem que carregar com ela, não'. Eu acho que ele começou a ficar um pouco cansado daquela situação.

Aqui se evidencia um outro aspecto da configuração subjetiva da doença em MG, a emergência de um posicionamento humano aberto em relação ao outro, reconhecendo os limites desse outro, respeitando-os. O caminho da vida não é uma expressão linear de caráter racional, mas o processo complexo de configuração subjetiva do vivido, que é o responsável pela motivação das opções do sujeito. Essa nova filosofia de vida, essa capacidade de produzir sentidos subjetivos capazes de acompanhar emocionalmente a superação de um egoísmo centrado na doença, representa um indicador de desenvolvimento da esfera moral, responsável por novos valores morais que passam a integrar a configuração subjetiva da doença, possibilitando a emergência de valores como o reconhecimento à independência do outro e sua responsabilidade pessoal frente à doença, sem assumir uma posição de vítima. Esse posicionamento descrito antes se revela também como um indicador da forma como 
ela assumiu a doença, como sua, sem romper sua identidade como pessoa. É a sua doença, e, portanto, tem que enfrentar todas as consequências que derivam dela, como é assumir as consequências de qualquer decisão pessoal que se toma na vida. Entre as pessoas com quem gosta de conversar até hoje, está o ex-marido. Esse elemento aparentemente insignificante é um importante indicador do tipo de emoção que acompanha as suas reflexões sobre o espaço do outro, um indicador do sentido subjetivo dos valores assinalados anteriormente.

Esse posicionamento moral próprio, unido à sua capacidade de produzir sentidos subjetivos nas diferentes áreas de sua vida e a sua capacidade para elaborar projetos para o futuro representam, pela relação entre eles, um importante indicador do desenvolvimento de sua identidade nas condições da doença; ela é capaz de reconhecer a si mesma em suas posições próprias e de gerar alternativas frente aos conflitos que vão aparecendo, frente aos quais se posiciona como protagonista. A identidade é um sistema vivo, em processo, de muita importância na produção de novos sentidos subjetivos frente às realidades imprevistas que vão aparecendo.

Essa orientação para o futuro, esses novos interesses e o significado de seu novo relacionamento ficam claros tanto nos trechos das conversações quanto no complemento de frases, no qual se destacam as seguintes:

- Gosto: de ler muito

- Sofro: quando passo mal

- Desejo: ficar curada

- O sucesso: fazer meu doutorado

- A felicidade: depende de mim

- Lamento: pela perda de meu pai

- Não posso: fazer mais judô

- O trabalho: minha terapia
- Casamento: vou casar com R. (namorado atual)

- Acredito que minhas melhores atitudes: nunca ter mágoa de ninguém

Nas frases acima, evidenciam-se a riqueza e diversidade de seus interesses e projetos. Nesse instrumento, ela revelou um tom emocional positivo em geral e também reconheceu seu sofrimento e o mal-estar da doença em frases pontuais, o que evidencia que ela não foge da doença, mas assume e reconhece a sua presença, sem fazer dela o centro de sua vida. É interessante observar que indutores diretos como fracassei, não gosto e lamento não estão associados à doença, o que representa um outro indicador de que ela não está centrada na doença e de que esta não monopoliza sua capacidade de malestar, expressando este em relação a outras motivações fortes de sua vida pessoal, como a perda do pai.

Outro elemento de sentido subjetivo importante no caso de MG é sua representação da doença em relação à sua vida pessoal, que é totalmente congruente com as construções que temos apresentado até aqui. Ela declara:

Eu penso que nada acontece por acaso... eu acho assim, eu estou aprendendo muita coisa, eu estou mudando como pessoa de uma forma assim, eu posso estar até doente na carne, mas tem muita coisa no meu consciente, no meu coração, psicologicamente falando, no meu espírito, que está sendo curado através dessa experiência.

Ela consegue ver a doença não como trauma ou fatalidade; a doença é também uma opção de vida! Novos sentidos subjetivos têm sido produzidos nesse viver doente, o que têm facilitado o acesso a novas experiências, o que tem permitido que ela veja novas coisas da vida. Esse sentir é uma experiência de vida e de crescimento pessoal que ela vivencia e reconhece e que representa outro indicador 
de sua identidade, da visibilidade que manteve em todo momento sobre si mesma e dessa capacidade de crescer a partir de novas dimensões de si mesma.

É muito interessante a construção teórica sobre o lugar do sujeito na produção de sentidos subjetivos sobre a doença: a construção, por parte de MG, de um sistema de relacionamentos favorecedores de sentidos subjetivos que vão na direção do bem-estar e do desenvolvimento de alternativas de vida frente à doença. Nesse sentido, ela expressa:

eu tenho pessoas que vestiram a camisa junto comigo, e elas podem até sofrer, mas elas não mostram na minha frente... O Paulo sempre foi um amigo de chegar e falar assim: 'olha, bola para frente, menina, levanta a cabeça, se você abaixar a cabeça, você não sai do lugar'. E é esse o tipo de amigo que eu preciso por perto... O Paulo às vezes é um pouco duro até demais. Ele faz igual ao meu ex-marido, que é um ótimo amigo.

Esse trecho evidencia seu posicionamento ativo em relação às pessoas, que é relevante em sua produção subjetiva atual. A última frase é um outro indicador, convergente com o que ela já tinha citado no complemento de frases, de não ser uma pessoa de guardar mágoas e ressentimentos, pois, de forma totalmente espontânea e em um contexto em que não lhe foi perguntado, ela reafirma o valor de seu ex-marido como amigo.

$\mathrm{Na}$ análise do presente caso, é interessante destacar como a configuração subjetiva da doença expressa sentidos subjetivos que se integram de forma inseparável em uma rede subjetiva. Não existem motivos simples e pontuais, existem fontes diferentes que, na sua integração, são as responsáveis pelos seus estados subjetivos dominantes: um envolvimento emocional e espontâneo com os filhos, um desfrutar de novas coisas que antes não era capaz de ver, uma filosofia do mundo que the permite assumir sua responsabilidade frente à doença, aproveitar do outro o melhor que ele tem para the oferecer são todos aspectos de sentido subjetivo que se relacionam como expressões da configuração subjetiva da doença, nos quais ela se reconhece no processo de viver nas condições da doença.

Esse sistema de sentidos diversos e em movimento, com seus múltiplos desdobramentos simbólicos e emocionais, forma a configuração subjetiva da doença, na qual as mudanças que afetam um dos aspectos envolvidos atuam como o início de um processo de mudança que afetará todo o sistema. É desse sistema subjetivo que, em última instância, se definem os estados psíquicos associados ao seu cotidiano.

Para MT, que também recebeu o diagnóstico de câncer durante a gravidez, esta se transformou também em um elemento de sentido subjetivo da doença, mesmo que os filhos, no seu caso, não tenham tido a mesma relevância subjetiva que para MG. Assim ela diz:

Eu não fiquei muito desesperada não, você leva um choque (refere-se ao momento do diagnóstico)... Não sei se a minha situação de gravidez me deu mais força para ficar mais tranquila, não tive os meus momentos de desespero, mas tive os meus momentos de tristeza... Mas acho que eu aceitei bem, a minha preocupação era resolver logo...

MT, desde o primeiro momento, se posiciona frente à doença, supera o impacto inicial e assume a decisão de enfrentar rapidamente a cirurgia. Ela se mostra firme quanto aos seus relacionamentos, aceitando somente aqueles que contribuíram com seu esforço para que ela transcendesse a doença e continuasse vivendo com objetivos e interesses. Mesmo tendo posicionamentos muitos semelhantes aos assumidos por MG como sujeito da 
doença, o sistema de sentidos da configuração subjetiva de MT é diferente, o que continua nos apoiando na ideia do caráter singular das configurações subjetivas.

No que diz respeito aos relacionamentos, ela valoriza a naturalidade dos outros ao falar da doença, e, em relação a isso, destaca:

...a gente conversava sobre o que eu estava fazendo, sobre o tratamento, conversava muito com o meu marido, qual era minha melhor opção... Eu achava bom quando a pessoa vinha e me perguntava: como é que é, caiu o cabelo mesmo? Com naturalidade, porque, na verdade, as pessoas têm muita curiosidade em saber, mesmo.

O fato de a pessoa assumir a sua condição de doente é uma expressão essencial do desenvolvimento de sua identidade frente ao forte impacto da doença, que lhe permitirá autorreconhecer-se em sua condição atual, e não negá-la ou ocultá-la. Disso decorre o mal-estar dessas duas pessoas ao não serem tratadas de forma espontânea, aberta, o que, de fato, representa a sua negação como pessoas.

A produção de identidade frente à nova situação da doença é essencial precisamente para se manter uma vida ativa e diversa, de tal forma que a doença não ocupe o centro, mantendo a pessoa seu envolvimento naquelas áreas que constituem sentidos subjetivos importantes de sua vida pessoal. Também de forma muito semelhante a MG, MT conserva seus interesses e se esforça para manter-se ativa. Ela assim se expressa quanto a isso:

Eu estava até agora de licença e, durante um bom tempo, eu até pensei em me aposentar, porque a doença dá chance de você se aposentar, mas desse ano para cá, desisti completamente dessa ideia, porque eu já não suportava mais ficar sem produzir, sem ir para o trabalho. Eu já estava contando os meses.
Repete-se, no relato de MT, algo que já tínhamos comentado na análise de MG, a importância das expressões associadas de forma espontânea pelo sujeito à ação, que são diferentes das que estão centradas em adjetivos de caráter descritivo que, com frequência, fazem parte de um estereótipo social de resposta positiva. Seu posicionamento ativo, engajado, interessado pela vida, não é declaração, aparece construído na representação da ação.

As declarações das pessoas não são lineares, não são as respostas que levam de forma direta à identificação dos sentidos subjetivos que estão na base dessas declarações. Na compreensão da subjetividade em que nos situamos, a configuração subjetiva representa um sistema de sentidos subjetivos muito complexo que, em seu relacionamento permanente, pode ter momentos muito diversos e contraditórios em contextos diferentes da vida do sujeito. Isso se evidenciou com clareza em MG e volta a aparecer no depoimento de MT, no qual se aprecia a sua mudança de decisão em relação ao trabalho.

Um processo essencial da identidade é a pessoa gostar de si mesma, em relação ao qual MT nos falou:

Na verdade, eu não conseguia emagrecer
(refere-se ao período da quimioterapia),
então eu estava engordando, estava careca,
e, como a quimio resseca muito os olhos, eu
não podia usar muito lente de contato, tinha
que ficar usando óculos. Foi um período que
eu me sentia muito mal, me sentia péssima,
esta parte de minha auto-estima... Enfim,
logo depois desse período, você sente uma
motivação, eu fui para a academia, fui malhar,
comecei a fazer regime, foi uma delícia, o
cabelo começou a crescer, começou a ficar
superlegal. Nossa, era muito bom!

Sua fala nos mostra como ela é capaz de reagir a seu aspecto físico, o que é mais 
um indicador da sua identidade e de seu posicionamento subjetivo diante da doença; esta não eliminou sua capacidade de sentir suas diferentes dimensões como ser humano, de permanecer ligada à vida, assim como de lutar para alcançar a melhora do seu aspecto físico, que é um sentido subjetivo importante para ela. O fato de o físico e de a aparência serem importantes para ela lhe permite confrontar-se com o meio da academia, assumir-se perante um espaço social de mulheres em geral jovens e bonitas, o que representa um importante indicador de sua capacidade para atuar e vencer dificuldades, aspecto essencial da saúde emocional. A expressão "Nossa, era muito bom!" revela sua capacidade de sentir alegria plena, que ela foi capaz de vivenciar suas conquistas em relação a seu corpo e sua aparência, o que denota sua identidade, denota que ela continua gostando de si mesma, que tem capacidade de lutar com as sequelas da doença e do tratamento.

MT, tal qual MG, tem uma grande quantidade de interesses e se posiciona de forma reflexiva frente à experiência da doença, que teve um impacto na sua subjetividade, mas, mesmo gerando sofrimento, esse estado não prevaleceu, mas integrou-se em um processo de produção subjetiva que representou um momento de desenvolvimento frente à situação vivida. Assim ela relatou tal situação, em outro momento da conversa:

Acho que hoje eu dou muito menos valor para o dinheiro, dou muito mais valor para a qualidade de vida, dou muito mais valor a você estar cercada pelas pessoas que você gosta, estar vivendo momentos bons, falando coisas boas, estar produzindo, trabalhando, porque, quando você tem um câncer, você tem a impressão de estar vendo a morte de perto, e todas essas coisas que fazem parte de seu dia a dia, que viram rotina, passam a ter um valor diferente, tudo é diferente. Aí teve um dia que... peguei aquele trânsito, estava um sol quente e eu dentro do carro, mas gente, que felicidade de estar no congestionamento, que coisa boa estar sentindo aquele calor, aquele sol, suando, aquele barulho... Era essa a impressão, a impressão que você está viva, está pulsando.

Observa-se a alegria de viver, de desfrutar a vida em suas pequenas coisas. $\mathrm{O}$ fato de estar vivo, que normalmente se naturaliza ao extremo de não ser percebido no prazer de ser, é desfrutado por ela em seus detalhes mais simples, os que, nesse momento, passam a ser mais uma fonte dos sentidos de sua configuração subjetiva atual. As novas emoções que aparecem em todo esse processo e o envolvimento reflexivo de MT com essa experiência se tornam uma fonte de novos sentidos, e aparecem expressões de sentido subjetivo associadas a sua esfera moral que estimulam nela uma sensibilidade especial em relação aos outros. No complemento de frases, ela escreve:

- Sofro : com a saúde de nosso país

- Sinto que estou melhor: quando estou em meu trabalho como voluntária no Hospital de Base

- Os estudos: gostaria de fazer enfermagem

- Vale a pena seguir: os meus ideais em termos de voluntariado

- Necessito: de saúde para continuar meu trabalho

Ela se refere a sua saúde somente em uma das frases do complemento; em geral, está centrada em seus interesses, entre os quais se destacam seu trabalho em prol dos outros, em particular com as pessoas carentes com câncer. A nova situação em que se encontra levou-a à produção de novos sentidos subjetivos, que possibilitaram que ela se envolvesse em novas atividades, como o voluntariado, dentro das quais desenvolveu novos valores, como sua sensibilidade e solidariedade com as pessoas de baixa renda que sofrem de câncer, e novos interesses, como o de ser enfermeira.

Todos esses elementos evidenciam uma nova configuração subjetiva associada a novas 
práticas sociais e à fundação de novos espaços sociais, que constituem a base subjetiva de seu posicionamento frente à doença e frente à vida.

\section{Considerações finais}

O câncer, em seu caráter objetivo, não define as configurações subjetivas que, frente a sua emergência, são desenvolvidas pelo sujeito e que the permitem diversas formas de viver e sentir subjetivamente essa experiência. A subjetividade não é um reflexo de uma condição objetiva, mas a capacidade de produzir alternativa frente à experiência vivida a partir dos recursos subjetivos atuais da pessoa.

É interessante destacar, nestas conclusões, que as respostas das pessoas nos instrumentos de fato expressam os próprios sentidos subjetivos que resultaram do processo de comunicação que caracterizou o desenvolvimento da pesquisa, no contexto da qual elas se entrosaram em atividades relacionais que promoveram a emergência de novas reflexões e emoções em relação ao câncer.

O sujeito e seus posicionamentos ativos frente aos outros são fatores essenciais na evolução subjetiva da doença. Foi observado, em ambos os sujeitos estudados, um posicionamento ativo frente à vida e aos outros, o que lhes permitiu criar sistemas de apoio social facilitadores de estados subjetivos favoráveis. Isso também Ihes tem permitido se assumir como sujeitos da doença e desenvolver uma nova identidade frente a ela, passando a produzir um novo mundo subjetivo em que a doença está incorporada a um sistema de sentidos subjetivos, e não negada.
O modelo de configuração subjetiva que apresentamos no trabalho permite-nos compreender a organização subjetiva da pessoa em seu caráter contraditório, processual e singular. $\mathrm{Na}$ configuração subjetiva do câncer, em cada paciente, são expressamse sentidos subjetivos contraditórios que mantêm uma relação de tensão entre si, que podem ser dominantes em diferentes momentos da expressão do sujeito segundo seus próprios estados subjetivos e a forma como se inserem nos diferentes contextos em sua vida cotidiana.

Como se evidencia nos casos que apresentamos, o câncer é uma doença portadora de forte carga social, que se expressa de diferentes formas nos sistemas de relacionamentos dos pacientes, mas seu sentido subjetivo será a produção singular de cada paciente, em que se articulam os aspectos sociais e emocionais que circunscrevem a vida de cada um.

A qualidade de vida do paciente com câncer está relacionada à possibilidade dos pacientes em conseguir produzir sentidos subjetivos que os envolvam emocionalmente em suas diferentes atividades e relacionamentos. Nos dois casos estudados, a diversidade de interesses, a capacidade de manter projetos, a determinação de luta e o envolvimento reflexivo com a doença constituem aspectos facilitadores do desenvolvimento do paciente na situação da doença.

Só o estudo de casos, com a diversidade de fontes de informação que permite e com a possibilidade de aprofundamento nessas fontes, seria capaz de nos fornecer essas informações diferenciadas que nos permitem avançar cada vez mais na compreensão das configurações subjetivas da doença e de sua relevância como fator da qualidade de vida e do desenvolvimento desses pacientes. 


\section{Fernando Luis González Rey}

Doutor em Psicologia. Professor titular do Centro Universitário de Brasília, Brasília, DF - Brasil.

\section{Endereço para envio de correspondência:}

SQS 407, Bloco R, ap. 206, Asa Sul - Brasília, DF - Brasil - CEP 70256-180.

E-mail: gonzalez_rey49@hotmail.com

Recebido 7/4/2009, 1a Reformulação 24/7/2009, Aprovado 15/8/2009. 


\section{Referências}

Adorno, T. ( 2001). Epistemología y ciencias sociales. Valencia: Frónesis.

Bakhtin, M. (1997). Raboty 1940 - Nachala 1960 godov (Trabalhos de 1940 - começo dos anos 60). In Sobranie sochinenii. T. 5 ( Obras Escolhidas T. 5). Moscou: Editora Smysl. (Sentido).

Bayer, C. (2004). As configurações de sentido subjetivo no câncer de mama. Dissertação de Mestrado em Psicologia Clínica, Universidade de Brasília, Brasília, DF.

Bourdieu, P., Chamboredon. J., \& Passeron, J.-C. (1975). E oficio del sociologo: presupuestos epistemologicos. México: Siglo XXI.

Bryman, A., \& Burguess, R. (1994). Developments in qualitative data analysis: An introduction. In A. Bryman \& R. Burguess (Eds.), Analyzing qualitative data (pp. 3-17). London: Routledge.

Castoriadis, C. (1982). A instituição imaginária da sociedade. São Paulo: Paz e Terra.

Danziger, K. (1990). Constructing the subject: Historical origins of psychological research. New York: Cambridge University Press.

Elliot, A. (1992). Social theory and psychoanalysis in transition. Oxford: Blackwell.

Gimenes, M. G. (1997). A teoria do enfrentamento e suas implicações para sucessos e insucessos em psiconcologia. In M. G. Gimenes \& M. H. Fávero (Eds.), A mulher e o câncer (pp. 23-42). Campinas: Psy.

González Rey, F. (1997). Epistemología cualitativa y subjetividad. São Paulo: EDUC.

González Rey, F. (1999). La investigación cualitativa en psicología: rumbos y desafios. São Paulo: EDUC.

González Rey, F. (2002). Sujeto y subjetividad: una aproximación histórico-cultural. México, DF: Thomson.

González Rey, F. ( 2004). Personalidade, saúde e modo de vida. São Paulo: Thomson.

González Rey, F. (2005). Pesquisa qualitativa e subjetividade: os processos de construção da informação. São Paulo: Thomson.
González Rey, F. (2007). Social and individual subjetivity from a historical cultural standpoint. Critical Social Studies, Outlines, 9(2), 3-14.

González Rey, F., \& Mitjans, A. (1989). La personalidad: su educación y desarrollo. Habana: Pueblo y Educación.

Guattari, F. (1992). Caosmose: um novo paradigma estético. Rio de Janeiro: Editora 34.

Koch, S. (1992). The nature and limits of psychological knowledge: Lesson of a century of qua science. In S. Koch \& D. Leary (Eds.), A century of psychology as science (pp. 74-99). Washington, D.C.: American Psychological Association

Merleau-Ponty, M. (1991). Signos. São Paulo: Martins Fontes.

Ribeiro, E. M. C. P. (1994). O paciente terminal e a família. In M. M. M. J. Carvalho (Coord.), Introdução à psiconcologia (pp. 197-218). Campinas: Psy.

Rubinstein, S. L. (1967). Princípios de psicología general. Habana: Edición Revolucionaria.

Schpet, G. (1996). Psykjologiya socialnova bitiya (A psicologia do ser social). Moscou: Voronosche.

Silva, G. (2005). O impacto do câncer na subjetividade de uma paciente. Trabalho de conclusão de curso (Psicologia). Centro Universitário de Brasília, Brasília, DF.

Touraine, A. (2004). A busca de si: diálogo sobre o sujeito. Rio de Janeiro: Bertrand.

Touraine, A. (2006). Um novo paradigma: para compreender o mundo de hoje. Petrópolis, RJ: Vozes.

Vigotski, L. S. (1984). K voprosy o psikhologii tvorchestva aktera (As questões da psicologia do ator criativo). In Sobranye sochinenya (Obras Escolhidas). Moscou: Pedagogika.

Vigotski, L. S. (1987). Thinking and speech. In R. Rieber \& A. Carton (Eds.), The collected works of L. S. Vigotski - Vol I (pp. 43-287). New York: Plenum Press. 